Acta Crystallographica Section E

Structure Reports

Online

ISSN 1600-5368

\section{Rajenahally S. Narasegowda, Hemmige S. Yathirajan ${ }^{a}$ and Michael Bolte ${ }^{b_{*}}$}

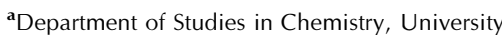
of Mysore, Manasagangotri, Mysore 570006 , India, and ${ }^{\mathbf{b}}$ Institut für Anorganische Chemie, J. W. Goethe-Universität Frankfurt, Marie-CurieStraße 11, 60439 Frankfurt/Main, Germany

Correspondence e-mail:

bolte@chemie.uni-frankfurt.de

\author{
Key indicators \\ Single-crystal $\mathrm{X}$-ray study \\ $T=173 \mathrm{~K}$ \\ Mean $\sigma(\mathrm{C}-\mathrm{C})=0.002 \AA$ \\ $R$ factor $=0.022$ \\ $w R$ factor $=0.057$ \\ Data-to-parameter ratio $=14.2$
}

For details of how these key indicators were automatically derived from the article, see http://journals.iucr.org/e.

\title{
Nipecotic acid hydrochloride
}

The title compound (3-carboxypiperidinium chloride), $\mathrm{C}_{6} \mathrm{H}_{12} \mathrm{NO}_{2}^{+} \cdot \mathrm{Cl}^{-}$, is the hydrochloride of nipecotic acid and is used as a drug intermediate and in the synthesis of $\gamma$-aminobutyric acid (GABA) uptake inhibitors. The geometric parameters are in the normal ranges. The crystal packing is stabilized by $\mathrm{O}-\mathrm{H} \cdots \mathrm{Cl}$ and $\mathrm{N}-\mathrm{H} \cdots \mathrm{Cl}$ hydrogen bonds.

\section{Comment}

Nipecotic acid or 3-piperidinecarboxylic acid is used as a drug intermediate and also in the synthesis of $\gamma$-aminobutyric acid (GABA) uptake inhibitors (Muralidhar et al., 1994). A review on the neurochemical and behavioural profile of a derivative of nipecotic acid hydrochloride has been reported by Suzdak \& Jansen (1995). In view of the importance of nipecotic acid, the present paper reports the crystal structure of nipecotic acid hydrochloride, (I).

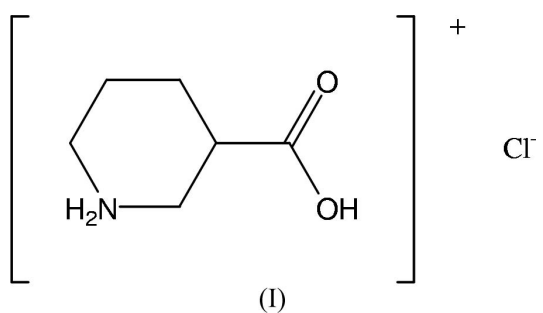

A perspective view of the title compound is shown in Fig. 1. Bond lengths and angles can be regarded as normal (Cambridge Structural Database, Version 1.7; Mogul Version 1.0.1; Allen, 2002). The heterocycle adopts a chair conformation. The crystal packing is stabilized by $\mathrm{O}-\mathrm{H} \cdots \mathrm{Cl}$ and $\mathrm{N}-\mathrm{H} \cdots \mathrm{Cl}$ hydrogen bonds.

\section{Experimental}

Nipecotic acid was purchased from the Aldrich Chemical Company and was converted to its hydrochloride by adding a mixture of isopropyl alcohol and hydrochloric acid (80/20). The compound was recrystallized from ethanol.
Received 10 February 2005 Accepted 17 February 2005 Online 26 February 2005

$$
\begin{aligned}
& \text { Crystal data } \\
& \mathrm{C}_{6} \mathrm{H}_{12} \mathrm{NO}_{2}^{+} \cdot \mathrm{Cl}^{-} \\
& M_{r}=165.62 \\
& \text { Monoclinic, } P 2_{1} \\
& a=7.2545(10) \AA \\
& b=7.2018(9) \AA \\
& c=7.7886(13) \AA \\
& \beta=97.819(12)^{\circ} \\
& V=403.14(10) \AA^{3} \\
& Z=2
\end{aligned}
$$

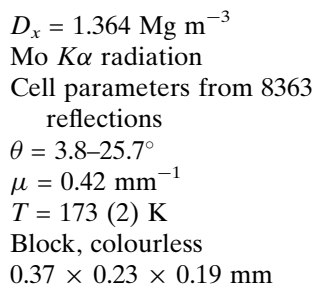




\section{organic papers}

\section{Data collection \\ Stoe IPDS-II two-circle diffractometer \\ $\omega$ scans \\ Absorption correction: multi-scan (MULABS; Spek, 2003; Blessing, 1995) \\ $T_{\min }=0.861, T_{\max }=0.925$ \\ 3354 measured reflections \\ Refinement \\ Refinement on $F^{2}$ \\ $R\left[F^{2}>2 \sigma\left(F^{2}\right)\right]=0.022$ \\ $w R\left(F^{2}\right)=0.057$ \\ $S=1.10$ \\ 1477 reflections \\ 104 parameters \\ $\mathrm{H}$ atoms treated by a mixture of independent and constrained refinement \\ 1477 independent reflections 1460 reflections with $I>2 \sigma(I)$ $R_{\text {int }}=0.020$ \\ $\theta_{\max }=25.5^{\circ}$ \\ $h=-8 \rightarrow 8$ \\ $k=-8 \rightarrow 8$ \\ $l=-9 \rightarrow 9$}

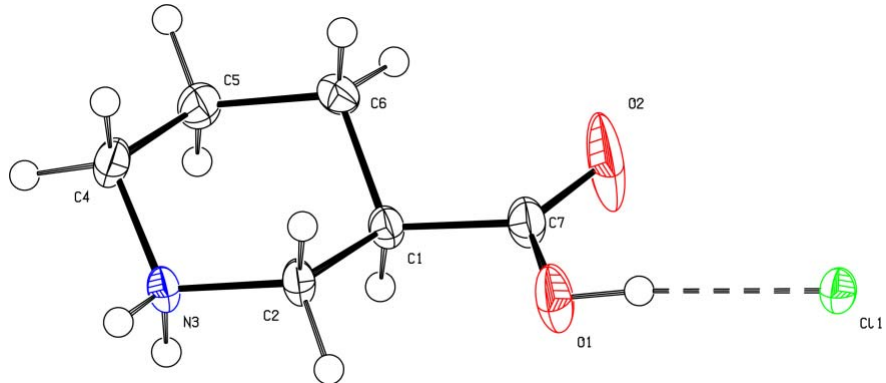

Figure 1

Perspective view of the title compound, showing the atom numbering and displacement ellipsoids drawn at the $50 \%$ probability level. The dashed line indicates a hydrogen bond.

using a riding model, with $\mathrm{C}-\mathrm{H}=0.99$ and $1.0 \AA$ for secondary and tertiary $\mathrm{H}$ atoms. The $\mathrm{H}$ atoms bonded to $\mathrm{N}$ and $\mathrm{O}$ atoms were refined freely. The ADDSYM routine in PLATON (Spek, 2003) detects a pseudo-centre of symmetry in the structure, which is fulfilled by approximately $80 \%$ of the structure. This would mean changing the space group from $P 2_{1}$ to $P 2_{1} / m$. In this case, the molecule must lie on a mirror plane. However, the molecule does not have any symmetry at all. Therefore, $P 2_{1}$ is the correct space group and it is just a pseudocentre of symmetry that $P L A T O N$ detects.

Data collection: $X$-AREA (Stoe \& Cie, 2001); cell refinement: $X$-AREA; data reduction: $X$-AREA; $\operatorname{program}(\mathrm{s})$ used to solve structure: SHELXS97 (Sheldrick, 1990); program(s) used to refine structure: SHELXL97 (Sheldrick, 1997); molecular graphics: PLATON (Spek, 2003); software used to prepare material for publication: SHELXL97 and PLATON.

\section{References}

Allen, F. H. (2002). Acta Cryst. B58, 380-388.

Blessing, R. H. (1995). Acta Cryst. A51, 33-38.

Flack, H. D. (1983). Acta Cryst. A39, 876-881.

Muralidhar, T. G., Borden, L. A., Tyagarajan, S., Smith, K. E., Branchek, T. A.,

Weinshank, R. L. \& Gluchowski, C. (1994). J. Med. Chem. 37, 2334-2342. Sheldrick, G. M. (1990). Acta Cryst. A46, 467-473.

Sheldrick, G. M. (1997). SHELXL97. University of Göttingen, Germany.

Spek, A. L. (2003). J. Appl. Cryst. 36, 7-13.

Stoe \& Cie (2001). X-AREA. Stoe \& Cie, Darmstadt, Germany

Suzdak, P. D. \& Jansen, J. A. (1995). Epilepsia, 36, 612-626. 